\title{
LAÇOS MAL-ATADOS COMO EFEITO DE FUNCIONAMENTO FALSO-SELF EM TEMPOS DE DESCONFIANÇA ${ }^{\mathrm{I}}$
}

\author{
Sandra Aparecida Serra Zanetti* \\ Isabel Cristina Gomes**
}

\section{RESUMo}

A contemporaneidade contempla formas de estruturação da subjetividade amplamente perpassadas por condições de existência socioculturais e econômicas. Estas, por sua vez, têm promovido laços intersubjetivos frágeis, cujo funcionamento psíquico pode ter uma organização de base "falso-self". Autores também demonstram que diversas instituições atuais se tornaram "fluidas" na passagem da modernidade para a "modernidade líquida". Isto contribuiu para a perda de referências sólidas que, outrora, davam sentido e direcionamento para o ser humano. Em decorrência há uma interferência direta na construção da "confiança madura", visto que os sinais de angústia da contemporaneidade podem ser um desorganizador do funcionamento psíquico, além de promoverem o isolamento, a desconfiança no ambiente e no outro, laços mal-atados e funcionamentos de base "falso-self".

Palavras-chave: laço social; amor; fatores psicossociais; contemporaneidade.

\section{Abstract}

\section{UNTIED TIES AS EFFECT OF FALSE-SELF FUNCTIONING IN TIMES OF MISTRUST}

The contemporaneity offers ways of structuring the subjectivity largely pervaded by the conditions of socio-cultural and economic existence. In turn, these have promoted fragile intersubjectives bonds, whose psychic functioning can have a base organization "false-self". Authors shows that many institutions today have become "fluid" in the passage from modernity to "liquid

* Psicóloga; Mestre e doutoranda do Departamento de Psicologia Clínica do Instituto de Psicologia da Universidade de São Paulo.

** Professora livre-docente do Departamento de Psicologia Clínica do Instituto de Psicologia da Universidade de São Paulo. 
modernity" and contributed to the loss of solid references that once gave meaning and direction to humans. This interferes directly in the construction of "mature confidence", because the distress signs in contemporaneity may be one disruptive psychic functioning, and to promote isolation, mistrust in environment and in the other, untied ties and functioning of base "false-self".

Keywords: social ties; love; psychosocial factors; contemporaneity.

\section{A CONTEMPORANEIDADE E SEUS DESENLACES}

A contemporaneidade contempla formas de estruturação da subjetividade amplamente perpassadas por condições de existência socioculturais e econômicas. Por sua vez, estas têm interferido, principalmente, no sentimento de confiança entre os indivíduos dessa época. Bauman (2001) é um dos autores que, ao analisar a conjuntura atual, percebe indivíduos cada vez mais solitários e imersos em suas preocupaçóes singulares, como consequência dessas condiçōes. Em Amor líquido, o autor procura chamar atenção para vidas pouco compartilhadas e laços mal-atados (Bauman, 2004).

Segundo o autor referido, para entender como se chegou a esse ponto é necessário perceber que, com o advento da modernidade, diversas instituições tornaram-se "fluidas". No projeto em busca da perfeição e da emancipação da humanidade, os construtores esforçaram-se por derreter todos os tipos de alianças e parcerias de compromisso que impediam o fluxo do capital de maneira que pudesse somente restar a lógica do lucro (Bauman, 2001). Assim, com o passar do tempo, os padrões de referência, as parcerias e todo tipo de relacionamento apoiado no compromisso, na honra e na solidariedade tornaram-se líquidos. A perda de referências sólidas, antes responsáveis por dar sentido e direcionamento ao ser humano, gerou um ambiente de insegurança e desconfiança, que se manifestam hoje nos diversos âmbitos dos relacionamentos. Em decorrência disto, surge uma sociedade organizada em torno do conceito de flexibilidade (Sennett, 2008), na qual as estratégias e os planos de vida só se dão em curto prazo. Os antigos padrões de referências, que envolviam a noção de continuidade e de permanência, se diluíram. Em vez disso, temos a instabilidade presente em todas as instâncias, principalmente em torno do trabalho.

O esforço por desancorar as relaçôes e transformar tudo que era sólido em líquido provocou também um capitalismo leve, segundo Bauman (2001). Hoje o capital segue solto, visto que nenhum administrador necessita mais de seu capital empregado em solo firme com trabalhadores fiéis, tornando assim as condições de trabalho incertas. $\mathrm{O}$ autor ressalta, ainda, que essa incerteza é de natureza temível, 
porque os desastres hoje ocorrem aleatoriamente e não há nada que se possa fazer para lutar, mesmo que se unam forças contra esse ataque que escolhe vítimas ao acaso. Além disso, essa incerteza do presente se transforma numa poderosa força individualizadora quando, nesse contexto, a ideia de interesse comum perde seu sentido.

Da mesma forma, para Lipovetsky (2004), na hipermodernidade ${ }^{2}$, como denomina essa era, há uma presença marcante do efêmero e, como consequência, a sensação de insegurança. Atribui esses fenômenos à rápida expansão do consumo, da comunicação de massa e da corrida pela competição, mas também ao enfraquecimento das normas autoritárias e disciplinares e ao surto da individualização, que consagrou o hedonismo e a sociedade de consumo. Essas características sustentam todo o processo por promover o novo e o mais interessante em detrimento do tradicional e do confiável. A lógica por detrás dos rumos da sociedade encontra-se sob o domínio de um sistema globalizado que se movimenta em função do lucro e não das necessidades dos seres humanos. $\mathrm{O}$ medo, a desesperança quanto ao futuro e a insegurança passaram a fazer parte da experiência cotidiana, para o autor.

A ideia do princípio da flexibilidade, para Sennett (2008), é a de que os indivíduos aprendam, principalmente, a se tornarem capazes de se desvincular do passado e da necessidade de confiança para aceitar a fragmentação. Este tipo de mentalidade é bastante atraente, pois parece produtiva e lucrativa para os capitalistas, que buscam hoje "alguém que prospera em meio ao deslocamento" (Sennett, 2008: 72). Entretanto, pode causar sofrimentos e angústias “juntamente com os deslocamentos sociais que acompanharam o seu sucesso" (Sennett, 2008: 72). Por isso, para o autor, este estado de funcionamento do mundo dos negócios interfere na personalidade dos indivíduos, que se tornam pouco solidários e indiferentes entre si em função de uma crise de orientação perante um mundo não-interpretável.

Nesse cenário, os medos, as angústias e as ansiedades decorrentes são feitos para serem sofridos em solidão, como mostra Bauman (2001), pois não somam nem se acumulam numa causa comum. Apoiando-se em Bourdieu (1998), Bauman (2001) acredita que a precariedade, a vulnerabilidade e a instabilidade são as características mais difundidas da vida contemporânea e não há no mundo quem escape delas.

Assim, uma das mais importantes consequências desse fenômeno social, para Bauman (2001), é que essa sociedade acaba por treinar homens e mulheres a perceber o mundo como um contêiner cheio de objetos descartáveis, inclusive de seres humanos. Os sinais incertos e propensos a mudar com rapidez nos ensinam, a todo o momento, que as ligações não devem ser indissolúveis e definitivas, pois tudo pode ser diferente num momento seguinte e será preciso mudar de casa, de companhia, tomar um avião e se afastar por um ano se preciso 
for. Ou seja, para Bauman (2001), a instabilidade da modernidade líquida levou à instabilidade nas relações.

No âmbito dos relacionamentos humanos, portanto, para esse autor a condição contemporânea implica em desencontros ou encontros frouxos, laços mal-atados promovidos pelos efeitos da conjuntura atual. Individualismo, competitividade, consumismo, insegurança, instabilidade, efemeridade e medo do futuro, que levam o indivíduo ao isolamento e à crença de que somente se pode confiar realmente em si mesmo. Giddens (1991) é outro autor que, apesar de concordar com o fato de que atualmente os relacionamentos carregam implicitamente uma falta de confiança generalizada, compreende um complexo sistema social que subjaz a esses fenômenos apontados pelos autores acima. Concorda que o ritmo das mudanças é sem precedentes no que tange à tecnologia e outras esferas e que, graças à globalização, ondas de transformações sociais afetam toda a superfície da Terra. No entanto, para ele, as causas desse dinamismo estão nas descontinuidades que separam as instituições sociais modernas das ordens sociais tradicionais.

Portanto, segundo esse autor, o dinamismo característico da modernidade deriva da separação das categorias de tempo e de espaço e de sua recombinação. Nas sociedades pré-modernas, tempo e espaço coincidiam amplamente; na modernidade, o espaço tem se desvinculado crescentemente do tempo porque as situaçóes vivenciais não mais necessitam ser localmente determinadas. Dessa separação observa-se o fenômeno que Giddens (1991: 129) descreve como "desencaixe", que retira as atividades sociais dos seus contextos. São dois os principais mecanismos de desencaixes: "as fichas simbólicas e os sistemas peritos" (Giddens, 1991: 30). Por ficha simbólica pode-se entender dinheiro. Já os sistemas peritos referem-se a procedimentos de excelência técnica ou de competência profissional que removem as relaçôes sociais das imediações do contexto e fornecem garantias por meio de uma relação espaço-tempo distanciada.

A “apropriação reflexiva do conhecimento" (Giddens, 1991: 44) é outro importante ponto de sustentação para o dinamismo da modernidade, segundo o autor. Nas culturas tradicionais o passado era honrado e os símbolos valorizados porque continham e perpetuavam a experiência de gerações. A reflexividade, no entanto, introduzida na base dos sistemas modernos, trata de pensamento e ação refratados entre si de forma constante; além de práticas sociais examinadas e reformuladas à luz de informação, que são renovadas sobre estas próprias práticas, alterando o caráter das mesmas. E a mais dura constatação, para este autor, está em perceber que, apesar de estarmos rodeados de conhecimentos reflexivos aplicados, "não podemos nunca estar seguros de que qualquer elemento dado deste conhecimento não será revisado" (Giddens, 1991: 46). Ou seja, nenhum conhecimento sob as condições 
da modernidade é conhecimento certo. Até mesmo filósofos como Popper, que defendem as reivindicaçôes da ciência à certeza, reconhecem que "toda ciência repousa sobre areia movediça” (Popper, citado por Giddens, 1991: 46).

Ancorado neste tipo de análise, Giddens (1991) defende que a contemporaneidade não deve ser entendida como um período novo, concebido na ideia de pós-modernidade, porque não reconhece que a modernidade tenha sido suplantada. Da mesma forma, Bauman (2001) e Lipovetsky (2004), depois de algum tempo, concordam que o termo pós-modernidade caiu em desuso e sustentam os termos modernidade líquida e hipermodernidade, respectivamente, porque todos percebem que "a modernidade não foi propriamente superada, mas sim levada a um extremo, mantendo suas características básicas que já apareciam no capitalismo primeiro, o capitalismo de acumulação" (Armony, 2009: 77-78).

Retomando o pensamento de Giddens (1991), há “aspectos da confiança e processos de desenvolvimento da personalidade que parecem se aplicar a todas as culturas" (Giddens, 1991: 95). Com base na psicanálise concebe o que denomina de "segurança ontológica": "a crença que a maioria dos seres humanos tem na continuidade de sua autoidentidade e na constância dos ambientes de ação social e material circundante" (Giddens, 1991: 95). Afirma que este fenômeno, de base emocional, tem suas raízes no inconsciente, algo que será tratado posteriormente. Contudo, também assegura que, se a confiança básica não é desenvolvida, o resultado é uma ansiedade existencial permanente.

Para este autor, nas culturas pré-modernas os cenários não podiam ser ditos como "psicologicamente aconchegantes" (Giddens, 1991: 107). Contudo, as evidências são claras de que no mundo moderno os níveis de insegurança ontológica são mais elevados do que na maioria das circunstâncias da vida social pré-moderna. Em condiçõos de modernidade, as três grandes forças do dinamismo - separação tempo-espaço, desencaixe e reflexividade - "desengajam certas formas básicas de relações de confiança dos atributos de contextos locais” (Giddens, 1991: 110). O declínio da família, o impacto decrescente da religião e da tradição são alguns exemplos. Além disso, o entrelaçamento entre o local e o global faz os ambientes terem pouca identidade. Ademais, na modernidade, os perigos não derivam somente da natureza, possuem intensidade maior e são de origens diversas: a possibilidade de uma guerra nuclear, os perigos advindos do mercado de investimentos, as calamidades ecológicas, as catástrofes potencialmente globais e, principalmente, o fato de que todo o conhecimento sobre os riscos não podem ser transformados em meios de controlá-los.

Portanto, é importante assinalar que Giddens (1991), por meios diferenciados de Bauman (2004) e Lipovetsky (2004), percebe no dinamismo e nos mecanismos 
de desencaixe da modernidade as bases para o processo generalizado de falta de confiança entre os indivíduos dessa época, gerando o que denomina de insegurança ontológica. Entretanto, trata-se de teorias complementares, pois os autores acabam por sinalizar diferentes aspectos das condiçōes socioculturais que levam ao mesmo enfraquecimento das bases que compõe o humano e dos laços sociais.

\section{COMPREENSÕES PSICANALÍTICAS SOBRE OS EFEITOS DA MODERNIDADE}

Neste segundo momento, pretende-se compreender os fenômenos socioculturais apresentados em termos do funcionamento psíquico que proporcionam. Como apontou Freud ([1921] 2006), parte-se da premissa de que a construção subjetiva de um indivíduo invariavelmente está envolvida com algo mais, um auxiliar, um oponente. Dessa maneira, desde as relações mais primitivas da infância, pode-se dizer que psicologia individual é também psicologia social. Assim, como propõe Salles (2005) com base em Berger e Luckmann (2002), Leontiev (1978) e Vygotsky (1993), a construção da subjetividade ocorre em meio às circunstâncias históricas, culturais e sociais nas quais o indivíduo está inserido, bem como por meio de experiências particulares que vivencia no interior de sua cultura.

Dessa forma, para o desenvolvimento de um raciocínio acerca de como o contexto sociocultural está ligado aos laços mal-atados por meio de um funcionamento "falso-self", será tomado como base o pensamento de Figueiredo (2007). Este autor analisa as condições sociais e psíquicas que dão suporte aos processos de constituição da "confiança" como condição para a saúde mental. Para tanto, baseou-se em elaboraçôes teóricas e clínicas de psicanalistas como Balint (1985a), Winnicott (1975) e Green (1984), tomando como base a interpretação da vida social e cultural contemporâneas de Giddens (1991), Giddens, Beck e Lash (1997) e de Elliott (2004).

As condições socioculturais atuais, conforme exposto, não favorecem aquilo que Giddens (1991) denomina de "segurança ontológica", ou seja, uma confiança no ambiente e em si mesmo que permitam que a vida seja vivida com prazer e tranquilidade. Pode-se pensar que uma sociedade que exige dos indivíduos flexibilidade, expondo-os altamente aos riscos do desemprego e da violência, estando eles imersos em um sistema que faz promessas de sucesso e gratificaçōes intensas, além de cultivar a expectativa de um final feliz nem sempre realizada, pede aos indivíduos que exercitem a sua capacidade de confiança, que, quando não muito bem constituída nos primórdios da vida, pode ficar permanentemente abalada. 
Para Balint (1985a), de acordo com Figueiredo (2007), a confiança nasce de uma sucessão feita de entrega, que evoca excitação, susto e medo, mas também, e principalmente, conforto recuperado. Aquilo que Balint (1985a) conceitua como thrill, associado às primeiras experiências lúdicas, relaciona-se com o estado do despertar pulsional causado por balanços, cócegas, diversas pequenas brincadeiras com a criança de levantá-la ou de jogá-la para cima, que propiciem experiências de tensão, mas também de relaxamento, que sempre terminam num abraço seguro.

Em "O brincar e a realidade" (Winnicott, 1975), de acordo com Figueiredo (2007), a criação do sentimento de confiança e do de desconfiança dependem da ligação com a mãe, ou substituta, e da sua capacidade de falhar de acordo com as possibilidades do bebê, basicamente de sua confiabilidade (reliability). O nascimento desta "confiança é a condição essencial do habitar e existir no próprio corpo - enraizar-se no soma e personalizar-se (Winnicott, 1970, citado por Figueiredo, 2007: 76) -, do brincar e da criação do espaço potencial (capacity to play and potential space) (Winnicott, 1971, citado por Figueiredo, 2007: 76). Portanto, a confiança se inicia com o "holding" materno na fase da dependência absoluta, que vai além da mera estabilidade: inclui "a capacidade da mãe de estabelecer uma relação harmônica e ritmada em que ela pode ser "inventada" pelo bebê e, ao mesmo tempo, ser ela mesma” (Figueiredo, 2007: 77). Caso as circunstâncias se desenvolvam de maneira desfavorável, a capacidade de ser criativo torna-se ausente ou precária, pois o bebê, sentindo-se pouco protegido, perde a capacidade de brincar e o símbolo significativo que se constitui através da experiência com objetos transicionais.

Será a partir de Green (1984) que Figueiredo (2007) conseguirá integrar as concepçôes de Balint (1985a, 1985b) e de Winnicott $(1971,1975)$ a respeito do nascimento da confiança e de seus abalos. A noção de "objeto primário" para Green (1984) - representado pela mãe, o ambiente ou o casal parental, com suas diferenciações de gênero - comporta a função de despertar e revelar a pulsão. Contudo, ao mesmo tempo, outro papel do "objeto primário" é o de conter e transformar a pulsão, "conforme as ideias de proveniência kleiniana e mais desenvolvidas por Bion (containment) e Winnicott (holding)" (Figueiredo, 2007: 80). Portanto, com base em Green (1984), Figueiredo (2007) concebe que o equilíbrio entre as funções do "objeto primário" de despertar e conter as pulsões é essencial para o estabelecimento da confiança, que aqui representaria o "objeto primário suficientemente bom” - parafraseando Winnicott $(1971,1975)$, pois o "objeto primário” seria o responsável por moderar a desproporção entre as sexualidades adulta e infantil.

Esquematicamente, Figueiredo (2007), elabora possíveis encadeamentos no processo de constituição da confiança. Inicialmente, tem-se o que denomina de 
“confiança primordial”. Esta se refere à expectativa de encontro com o "objeto primário suficientemente bom” (Figueiredo, 2007: 81) que não chega a ser experimentada como confiança, nem desconfiança, apenas uma "pré-concepção vazia" (Figueiredo, 2007: 81). No contato com o "objeto primário" os acontecimentos se desenvolvem de modo favorável ou não. Em caso desfavorável, a pré-concepção converte-se, num plano inconsciente e às vezes consciente, em desconfiança básica, que no plano da consciência pode se manifestar como uma "confiança defensiva", idealizada, como uma "pseudoconfiança” (Figueiredo, 2007: 81). Quando a pré-concepção se realiza de forma positiva, desenvolve-se a confiança primária, levando à internalização do objeto primário e ao estabelecimento da estrutura enquadrante, condição para a função objetalizante. No entanto, somente se a condição anterior se mantém e se sustenta diante de objetos ausentes, tem-se o estado de confiança madura, que comporta a capacidade de avaliação dos riscos, de maneira não idealizada, podendo julgar as experiências, aguardar o conhecimento delas e decidir-se pela confiança ou não. Ou seja, há o espaço para o não-confiar, o não-confiar ainda e o confiar.

A confiança madura, para Figueiredo (2007: 81), "supõe a ultrapassagem das posiçôes esquizo-paranoide e depressiva em que a desconfiança correspondente aflora com facilidade", como "desconfiança paranoica do outro" ou como "desconfiança de mim”, respectivamente.

Dessa forma, Figueiredo (2007), apoiando-se na leitura de Giddens (1991), compreende que o que este autor concebe como segurança ontológica se relaciona com o estado de confiança madura e se opõe ao estado que o autor denomina de ansiedade existencial e de fobia generalizada, tal como observa nos dias de hoje em termos de um fenômeno de massa. Figueiredo (2007) compreende ainda que os "pacientes desconfiados" de Balint (1985a, 1985b), "esquizoides" e "falso-selves", de Winnicott (1971, 1975), e borderlines indicam "a importância do que Green denominou de posição fóbica central nos atendimentos de casos difíceis" (Green, 2000, citado por Figueiredo, 2007: 82), em que todo o funcionamento psíquico fica comprometido pelo estado da desconfiança, da suspeita e pela impossibilidade de fazer contato com o intolerável.

Debruçando-se no cenário atual, portanto, Figueiredo (2007) compreende essa sociedade como uma "sociedade de risco" (Figueiredo, 2007: 83; Giddens et al., 1997), em que "os riscos estão associados a condições extremas de concorrência e promessas sedutoras de gozo que geram um estado crônico de superexcitação e medo" (Figueiredo, 2007: 83). Neste contexto,

o "sinal de angústia" pode-se tornar ininterrupto, o que o desqualifica para as funçôes de ativação de defesas egoica e tende a torná-lo um desorganizador do 
funcionamento psíquico de indivíduos e coletividades; o pânico em forma latente ou manifesta ocupa um lugar importante na vida emocional contemporânea e pode irromper pelos mais diversos incidentes; alastrando-se de forma rápida e incontrolável (Figueiredo, 2007: 84).

Portanto, assim como o "objeto primário" falho, a desproporção entre excitação e continência presente em nossa sociedade faz da desconfiança no ambiente e no outro um dos ingredientes básicos, segundo Figueiredo (2007), do mal-estar contemporâneo. Pode-se compreender a partir deste autor que a sociedade atual, comportando elementos semelhantes de um objeto primário falho, proporciona um mal-estar e sentimentos de desconfiança no indivíduo. Contudo, o modo como se compreende neste texto essa passagem será explicitado na sequência.

\section{O “FALSO-SELF” COMO ORGANIZADOR PSÍQUICO DOS LAÇOS MAL- ATADOS EM TEMPOS DE DESCONFIANÇA}

Apesar de o aspecto ameaçador desses elementos ser uma característica constante em nossa sociedade, Giddens (1991) nota que existe um sentimento generalizado de insensibilidade quanto a eles, quase de tédio. Este poderia ser compreendido como um mecanismo de defesa frente à impossibilidade de viver em estado de alerta constante em relação a todos eles. Entretanto, Giddens (1991) salienta apenas que esse estado certamente cobra um preço: a repressão da ansiedade esconde uma sensação de pavor que tende a instalar "sentimentos inconscientes sobre as incertezas enfrentadas pela humanidade como um todo" (Giddens, 1991: 135).

Figueiredo (2003) assegura que em condições desfavoráveis, em que o holding se torna uma experiência falha e o indivíduo não desenvolve a confiança madura, pode "ser acionada a defesa da desintegração, uma ativa produção de caos" (Figueiredo, 2003: 23). Além deste mecanismo de defesa, compreende o falso-self de Winnicott $(1971,1975)$ um tipo de dissociação decorrente também da falta de desenvolvimento de confiança no ambiente, do qual o indivíduo quer proteger o "verdadeiro self.

Winnicott (1989) enfatizou a importância da influência do meio ambiente no desenvolvimento psíquico do ser humano. No início, a presença e o cuidado maternos, por meio da capacidade que a mãe possui de se identificar com as necessidades do bebê, irão protegê-lo de suas angústias, possibilitando o processo de integração e de sua organização psíquica. A mãe suficientemente boa, dessa 
forma, permite ao bebê desenvolver-se fundamentado em suas tendências inatas, podendo experimentar um sentimento de continuidade da vida, que é o sinal da emergência de um verdadeiro self.

Assim como a mãe suficientemente boa, a cultura, com um papel secundário e de continuidade ao papel da mãe, permite ao indivíduo ser criador e sentir-se como real. Como propõe Kaës (2005), para o indivíduo adulto, a experiência cultural poderia se assemelhar à experiência de acolhimento e segurança vivida na primeira infância, pois funciona como um mediador, um espaço transicional. A área cultural e transicional assemelhar-se-iam por manter sem crise nem conflito a capacidade de coexistência do que já está lá e do ainda não advindo, da herança e da criação: espaços capazes de criar a ilusão fundadora de continuidade entre a realidade psíquica e a realidade externa.

Para Winnicott (1989) o ato de criar é muito importante, nele o ser humano põe em marcha seu desenvolvimento, buscando a possibilidade de encontrar uma realidade que o represente, só podendo realizar-se na medida em que for possível recriar a realidade a partir da própria subjetividade. Esta capacidade de simbolização e de criação, possibilitada pelo desenvolvimento sadio, como aponta Kaës (2005), serão as experiências capazes de introduzir a experiência cultural. Ou seja, possibilitam o nascimento do espaço intermediário que será continuado no espaço da cultura.

Contudo, Kaës (2005) assinala que o mal-estar em nosso mundo moderno, também diagnosticado pelos autores acima (Bauman, 2001; Figueiredo, 2007; Giddens, 1991; Lipovetsky, 2004), decorre das múltiplas transformações socioculturais e interfere nesta função da cultura. $\mathrm{O}$ autor considera que essas mudanças "põem em xeque as crenças e os mitos que asseguram a base narcísica de nosso pertencimento a um conjunto social" (Kaës, 2005: 53), comprometem os fundamentos da identidade, a base segura da convivência necessária para a vida em comunidade, e provocam falhas nos processos de apoio e de continuidade.

Ou seja, para Kaës (2005), as transformações em nível global afetam o sentimento de pertencimento a um grupo, provocando falhas nos processos intermediários possibilitados pela cultura. Isto porque na base da formação e manutenção da cultura está um processo intermediário, possibilitado pela capacidade de sublimação, em que o indivíduo só se submete à necessidade de controlar sua pulsão por encontrar a vantagem de conviver em segurança (Freud, [1929] 2006). As transformações atuais, contudo, afetam a base segura da convivência, pois não garantem mais a segurança necessária para a vida em comunidade. Para este autor, na contemporaneidade, a cultura, enquanto capaz de proporcionar um ambiente suficientemente bom e facilitador do processo, de promover uma ponte entre a realidade interna e externa, desempenha de modo falho essa função. 
Neste trabalho essa leitura de Kaës é fundamental. Parte-se da premissa de que tal como mãe - que pôde desempenhar suficientemente bem seu papel e oferecer ao bebê a experiência do controle mágico e o fruir das experiências em função do campo intersubjetivo de confiança - a cultura, quando pode desempenhar suficientemente bem o seu papel, é como a mãe suficientemente boa que cria um playground intermediário, no qual a ideia da magia se origina. A comparação entre a mãe suficientemente boa e a cultura, entretanto, é restrita, porque a segunda jamais poderá substituir a primeira. É necessário, como propôs Figueiredo (2007), que a confiança madura se instale nos primórdios da vida para que o indivíduo possa se beneficiar do posterior contato com a cultura.

No entanto, quando as condições de existência não sustentam um espaço sociocultural potencial, porque os elementos que compõem o quadro causam sensação de mal-estar e insegurança, a suposição é a de que indivíduos que não puderam se beneficiar de uma construção do sentimento de confiança madura no início da vida possam desenvolver também o oposto de uma estrutura psíquica integrada e verdadeira. Nesse caso o funcionamento falso-self poderia aparecer como mecanismo de defesa frente a um ambiente pouco confiável e fragmentador, ou seja, quando se sente o perigo de o verdadeiro self ser ferido. O tédio, então, observado por Giddens (1991), poderia ser compreendido como um componente de uma de organização falsa, que impede a expressão do eu verdadeiro já que, como propõe Winnicott (1989), o tédio resulta do tamponamento da vida criativa.

Concluindo, a partir da construção deste texto, o que se tem é uma possivel leitura de como os laços mal-atados poderiam ser pensados. Em decorrência de estados de funcionamento falso-selfse evita o encontro com a alteridade em função do medo generalizado e da desconfiança instalados em nossa sociedade. Nos indivíduos de funcionamento falso-self a experiência de prazer e fruição foi perdida, e sua estratégia de sobrevivência os coloca numa posição esvaziada de si mesmos. Sob o funcionamento defendido, os laços só podem ser frouxos ou mal-atados porque a proteção e a defesa psíquica os impede do contato profundo com o outro que, por extensão do ambiente que os cerca, é ameaçador e pouco confiável.

\section{CoNSIDERAÇÕES Finais}

De acordo com Winnicott (1989), quando o ambiente não é um facilitador para a organização psíquica, este pode favorecer o surgimento de um funcionamento falso-self. Este texto permite refletir que as condiçōes de existência atuais proporcionam uma experiência fragmentadora e desorganizadora, principalmente 
quando o indivíduo não pôde contar com a constituição de um self integrado e verdadeiro. Isto se dá porque este indivíduo terá menos recursos para se organizar perante o contexto atual. Dessa forma, os laços mal-atados poderiam ser lidos enquanto decorrência de um ambiente que proporciona sentimentos de desconfiança entre os indivíduos por não conseguirem contar com o espaço cultural potencial para organizarem-se psiquicamente.

A leitura de Kaës (2005) sobre a função de intermediária da cultura é central nesse pensamento. Pois é justamente neste ponto que, falhando essa função, atinge-se o funcionamento psíquico dos indivíduos, desestruturando aquilo que sustenta o laço, todas as formas de ligação, de intermediação e continuidade entre realidade interna e externa. Falhando em sua função de intermediária, a cultura promove o oposto de indivíduos compromissados e interessados entre si. Há uma quebra na sensação de continuidade do ser, que se recolhe.

Portanto, neste texto as contribuiçōes teóricas apresentadas e discutidas foram importantes para o entendimento de como os laços mal-atados podem estar relacionados ao contexto sociocultural e ao funcionamento falso-self. Entretanto, é importante salientar que essa é uma possibilidade de leitura e que esses quadros, ainda que ocorram como foram pensados neste texto, não serão vivenciados como patológicos por todos, nem todo o tempo.

\section{REFERÊNCIAS}

Armony, N. (2009). Confrontando Winnicott com os azares da hipermodernidade. Cadernos de Psicanálise SPCRJ, 25 (28), 77-119.

Balint, M. (1985a). Thrills and regression. London: Karnac.

Balint, M. (1985b). Primary love and psycho-analytic technique. London: Karnac.

Bauman, Z. (2001). Modernidade líquida. Rio de Janeiro: Jorge Zahar Editor.

Bauman, Z. (2004). Amor líquido: sobre a fragilidade dos laços contemporâneos. Rio de Janeiro: Jorge Zahar Editor.

Berger, P., \& Luckmann, T. A. (2002). A construção social da realidade. Tratado de sociologia do conhecimento. Rio de Janeiro: Vozes.

Bourdieu, P. (1998). Contrafogos: táticas para enfrentar a invasão neo-liberal. Rio de Janeiro: Jorge Zahar Editor.

Elliott, A. (2004). Subject to ourselves. Social theory, psychoanalysis and post modernity. London: Paradigm Publishers.

Figueiredo, L. C. M. (2003). Elementos para a clínica contemporânea. São Paulo: Escuta.

Figueiredo, L. C. M. (2007). Confiança: a experiência de confiar na clínica psicanalítica e no plano da cultura. Revista Brasileira de Psicanálise, 41 (3), 69-87. 
Freud, S. (1921/2006). Psicologia de grupo e a análise do ego. Obras completas, ESB, v. XVIII. Rio de Janeiro: Imago.

Freud, S. (1929/2006). O mal-estar na civilização. Obras completas, ESB, v. XXI. Rio de Janeiro: Imago.

Giddens, A. (1991). As consequências da modernidade. São Paulo: Unesp.

Giddens, A., Beck. U., \& Lash, S. (1997). Modernização reflexiva. Política, tradição e estética na ordem social moderna. São Paulo: Unesp.

Green, A. (1984). Propédeutique. La métapsychologie revisitée. Paris: Champ Vallon.

Kaës, R. (2005). Espaços psíquicos compartilhados: transmissão e negatividade. São Paulo: Casa do Psicólogo.

Leontiev, A. N. (1978). Actividad, conciencia y personalidad. Buenos Aires: Ediciones Ciências del Hombre.

Lipovetsky, G. (2004). Os tempos hipermodernos. São Paulo: Editora Barcarolla.

Salles, L. M. F. (2005). Infância e adolescência na sociedade contemporânea: alguns apontamentos. Estudos de Psicologia (Campinas), 22 (1), 33-41.

Sennett, R. (2008). A corrosão do caráter. Rio de Janeiro: Record.

Vygotsky, L. S. (1993). Pensamento e linguagem. São Paulo: Martins Fontes.

Winnicott, D. W. (1971). A criança e seu mundo. Tradução de Álvaro Cabral. Rio de Janeiro: Zahar Editores.

Winnicott, D. W. (1975). O brincar e a realidade. Rio de Janeiro: Imago.

Winnicott, D. W. (1989). Tudo começa em casa. São Paulo: Martins Fontes.

\section{Notas}

I Trabalho derivado de tese de doutorado em andamento no Instituto de Psicologia da Universidade de São Paulo com apoio das agências de fomento CAPES e FAPESP, às quais agradecemos.

2 Importante informar ao leitor que neste texto não se pretende entrar em discussões profundas em relação a como denominar a contemporaneidade porque este trabalho tem outros fins. O que se pretende é extrair dos autores, independentemente do seu posicionamento terminológico, o modo como compreendem as condições socioculturais e econômicas atuais para delas beneficiar-se no entendimento do fenômeno estudado.

Recebido em 24 de novembro de 2010 Aceito para publicação em 10 de março de 2011 